\title{
Metal-Free Arylation of Phenols and Carboxylic Acids
}

\section{Berit Olofsson}

\section{Department of Organic Chemistry, Arrhenius Laboratory, Stockholm University, 10691 Stockholm, Sweden}

\author{
*e-mail: berit@organ.su.se
}

Keywords: diaryliodonium salts, hypervalent iodine compounds, diaryl ethers

\section{INTRODUCTION}

Diaryl ethers and aryl esters are common structural features in pharmaceuticals, agrochemicals, polymers and numerous natural products. Despite more than a century of immense focus on finding efficient synthetic routes to these compound classes, the synthesis of substituted diaryl ethers and aryl esters remain difficult. ${ }^{1}$

The use of diaryliodonium salts has recently gained considerable attention in organic synthesis. Their properties allow for both metal-catalyzed and metalfree reactions, avoiding the drawbacks of organometallic chemistry, such as cost, toxicity, and threshold values in pharmaceutical products. ${ }^{2}$

We have developed several efficient one-pot routes to diaryliodonium salts, and these compounds are now inexpensive and easily available (Scheme 1). ${ }^{3}$

Scheme 1. One-Pot Synthesis of Diaryliodonium Salts

$$
\begin{aligned}
& A r^{1}-\mathrm{I}+\mathrm{Ar}^{2}-\mathrm{H} \\
& \text { or } \\
& \mathrm{I}_{2}+\mathrm{Ar}-\mathrm{H}
\end{aligned}
$$

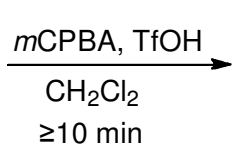

We are presently investigating these selective and nontoxic reagents as electrophilic arylating agents, ${ }^{4}$ and herein we present our results on the arylation of phenols and carboxylic acids. ${ }^{4 \mathrm{~b}-\mathrm{c}}$

\section{RESULTS AND DISCUSSION}

The arylation of phenols with diaryliodonium salts proceeds at room temperature to give diaryl ethers in high yields (Scheme 2). The reaction time can be shortened to 15 minutes by heating to $40{ }^{\circ} \mathrm{C}$. The metal-free conditions are compatible with a range of functional groups, including heteroaromatics, halides and racemization-prone amino acid derivatives.

Scheme 2. Synthesis of Diaryl Ethers<smiles>OC1=CC=[R]#CC=C1</smiles>

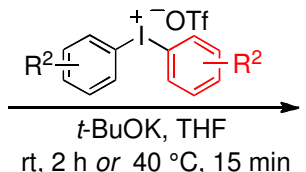<smiles>[R][R]1ccc(Oc2ccc[R17]([O-])c2)cc1</smiles>

The reactions were run without precautions to avoid air or moisture. $t$-BuOK was chosen as base for practical reasons, but $\mathrm{NaOH}$ can also be employed.
We subsequently developed a route to aryl esters by metal-free arylation of carboxylates (Scheme 3). Good to excellent yields were obtained without the use of metal catalysts, halogenated solvents or excess reagents. Aryl esters can be synthesized in the presence of primary alcohols, N-Boc substituents and ketones, and both aromatic and aliphatic substrates are tolerated. The scope includes synthesis of remarkably hindered esters, which are impossible to obtain via other esterification methods.

Scheme 3. Synthesis of Aryl Esters
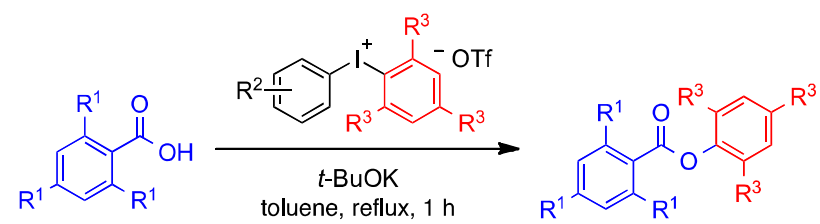

$68-97 \%$

\section{CONCLUSION}

Fast and high-yielding routes to diaryl ethers and aryl esters have been developed using mild and metal-free conditions. The scope includes many functional groups and bulky ortho-substituted products, which are difficult to obtain by metalcatalyzed protocols.

The methodology is expected to be of high utility in the synthesis of complex molecules and in the pharmaceutical industry.

\section{ACKNOWLEDGEMENTS}

This work was financially supported by the Swedish Research Council, STINT, the Carl Trygger Foundation, Bergvalls Foundation, the Higher Education Commission of Pakistan and CNPq.

\section{REFERENCES}

1 a) Sawyer, J. S. Tetrahedron 2000, 56, 5045. b) Otera, J.; Nishikido, J., Esterification. $2^{\text {nd }}$ ed.; Wiley-WCH: Weinheim, 2009. 2 a) Merritt, E. A.; Olofsson, B. Angew. Chem. Int. Ed. 2009, 48, 9052. b) Zhdankin, V. V.; Stang, P. J. Chem. Rev. 2008, 108, 5299 .

3 a) Bielawski, M.; Aili, D.; Olofsson, B. J. Org. Chem. 2008, 73, 4602. b) Bielawski, M.; Zhu, M.; Olofsson, B. Adv. Synth. Catal. 2007, 349, 2610. c) Merritt, E. A.; Malmgren, J.; Klinke, F. J.; Olofsson, B. Synlett 2009, 2277. d) Zhu, M.; Jalalian, N.; Olofsson, B. Synlett 2008, 592.

4 a) Norrby, P.-O.; Petersen, T. B.; Bielawski, M.; Olofsson, B. Chem. Eur. J. 2010, 16, 8251. b) Jalalian, N.; Ishikawa, E. E.; Silva, L. F.; Olofsson, B. Org. Lett. 2011, 13, 1552. c) Petersen, T. B.; Khan, R.; Olofsson, B. Submitted. 